\title{
Learning from Pandemics in the Americas: The Dominican Republic Programmatic Response Against a novel Coronavirus (COVID-19)
}

\author{
Robert Paulino-Ramírez \\ Leandro Tapia'
}

In the most recent Global Health Security Index (GHS) report Latin American countries [1] are less prepared to respond to a sanitary catastrophe. The index evaluates each country capability in preventing, detecting, responding, health care provision, regulations, and risk environment. Based on this, Latin American countries' classification varies between the most prepared (50-67 ranking) (e.g., Brazil, Argentina) to least prepared (33-50 ranking) (e.g., Dominican Republic, Colombia, Peru). In general, the regional preparedness consists of detection and reporting capacity (only 19\%), and fewer than $7 \%$ of Latin American countries scored in the highest tier for the ability to prevent and mitigate the emergence or release of pathogens. According to this report, the Dominican Republic scores below the global average in the following categories: 1. Prevention of the emergence or release of pathogens; 2 . Early detection \& reporting for epidemics of potential international concern; 3. Rapid response to and mitigation of the spread of an epidemic; and 4. Sufficient $\&$ robust health system to treat the sick \& protect health workers.

The newly introduced severe acute respiratory syndrome coronavirus 2 (SARS-CoV-2) causative agent of coronavirus disease 2019 (COVID-19) was confirmed in the Dominican Republic on the 29th of February 2020. Today, COVID-19 cases accounts for 6293 and a mortality of $4.5 \%$ [Figure 1] [2]. DR as other countries from the Caribbean region has a service-based economy, which mostly depends on the touristic industry. Localized at the gates of the Americas with stunting beaches, and effective road connectivity, it is highly attractive for tourists from across the globe, and appealing to the increasing rate of newly imported pathogens.

\footnotetext{
${ }^{1}$ Instituto de Medicina Tropical \& Salud Global, Universidad Iberoamericana, Santo Domingo, Dominican Republic, 22333

$\square \square \square \square$

Como citar este artigo / How to cite this article
}

Paulino-Ramírez R, Tapia L. Learning from Pandemics in the Americas: The Dominican Republic Programmatic Response Against a novel Corornavirus (COVID-19). InterAm J Med Health 2020;3:e202003024. 


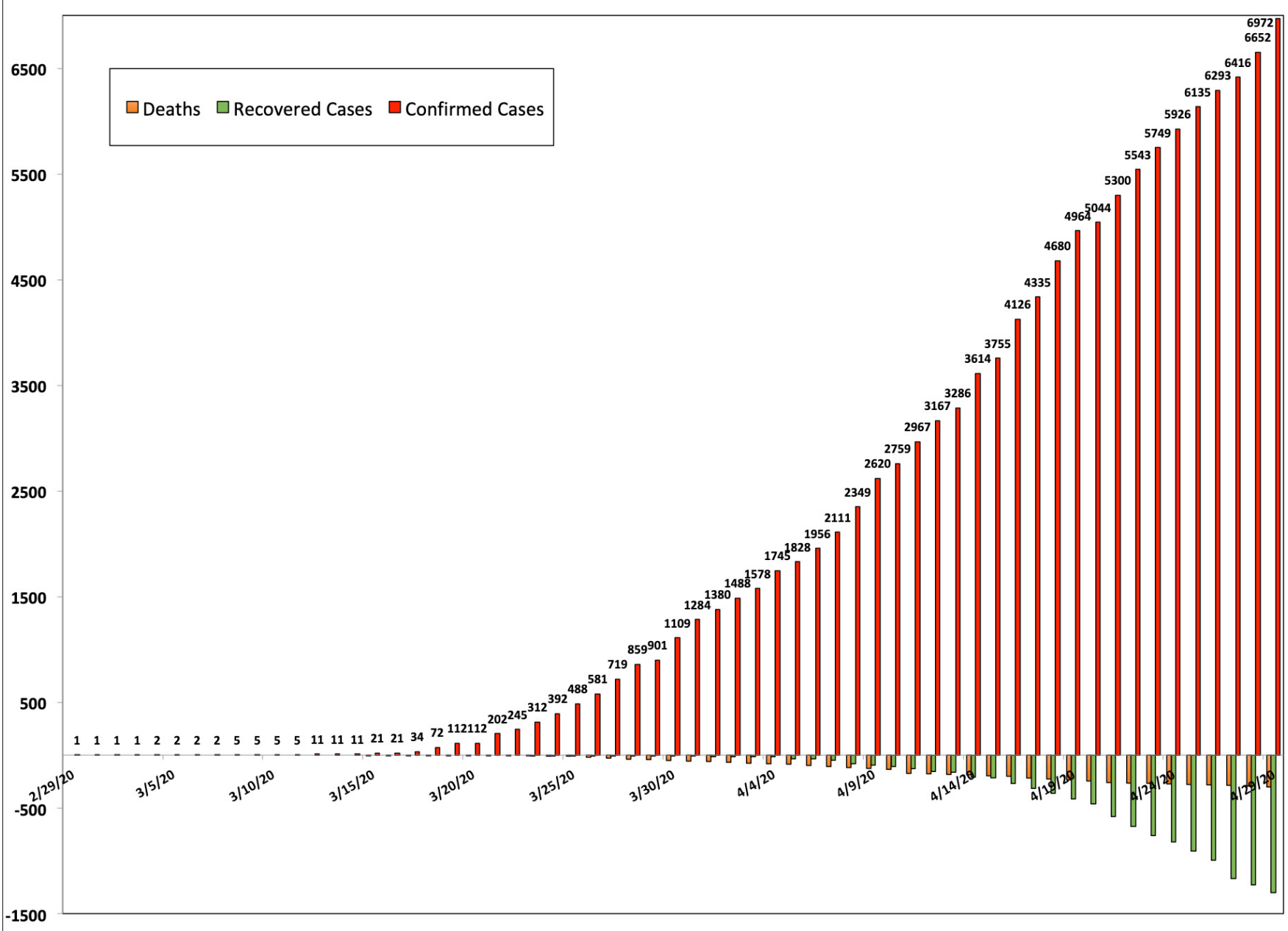

The country is not alien to health challenges caused by emerging and re-

emerging pathogens. During the last decade, infectious disease outbreaks caused by Chikungunya, Zika, Dengue viruses [3,4] and Malaria has caused rapid nationwide outbreaks [5]. In contrast, pathogens such as HIV and tuberculosis are following a syndemic pattern in the island; the HIV epidemic was in the early ages considered a hidden disease, provoking affected individuals especially susceptible to stigmatization. HIV viral machinery still affects marginalized communities like female sex workers, men having sex with other men and migrants, specifically from Haitian origin, circulating in clusters of transmission, facilitating a more extensive spread across many localities [6]. Strategies to limit and reduce harm from chronic infections are also applicable to acute illnesses caused by SARS-CoV-2 [7].
After only five months from the early recognition of the causative agent of a pneumonia-like severe illness in China, examples on how tackle the epidemic arised [8]. Hubei province government strictly quarantined Wuhan City during several weeks. This intervention was guided by a susceptible exposed infectious recovered (SEIR) compa allowed the health system to adequately respond to sever cases [9]. Today China has no new reported in severe cases [9]. Today, China has no new reported infections, except those imported from countries on-going the epidemiological phase that occurred three months ago. But, shall we say that population quarantine is the most effective preventive measure to cause the incidence curve to flatten?

Other countries have carried out similar actions: however, their health systems have collapsed, and they are insufficient to treat aggravated cases, such as the case of
Italy [10]. What failed in Italy? In general, the dangerous complacency of the systems before the implementation of social distancing, allowing continuous social conglomerates, people to circulate and perform activities that increased
economy.

Thirdly, we have the Germany' experience; it has reported up to 6,126 deaths (3.8\% mortality rate) out of a total of 158,758 confirmed cases, what has caused the high infectious rate virus not to generate as many deaths? When we analyze the natural history of the virus, we find three phases; among them, there may be contagiousness. Therefore, carrying out, whenever possible, intensive case detections will lead to focalized transm case detections will lead to focalized transmission reduction measurements leading to increased precision upon implementation, and the need for social isolation strengthened. During this first phase, the country has been using experimental antivirals and other drug interventions that appear to reduce the inflammatory response, as well as mortality.

Similar to Germany is South Korea that flattened the incidence curve without shutting down the economy. Instead, South Korea used a smart and aggressive public health strategy. Within a week from the first confirmed case, the government urged companies to immediately start-developing COVID-19 test kits for mass production [11]. Within two weeks, thousands of test kits were shipping daily. South Korean authorities conducted more than 300,000 tests: this enabled them to isolate and treat many people soon after they are infected, minimizing further spread. Previous experiences with other zoorotic coronavirus (e. MERS) in South Korea potentiated the molecular biology infrastructure in preparation for a new pandemic.

Foundations of global health are cemented in learning from effective interventions in preparation for future emergencies. The Caribbean is the second largest region in the world affected by the HIV pandemic. The fight against HIV takes a community-centred approach, where massive efforts guide the testing services and linkage to nearby HIV clinics for drug provision. Community navigators are aimed to increase testing capacities and had provided community antiretroviral delivery, enhancing the adherence of the most marginalized populations. In contrast, the fight against COVID-19 takes an inverse approach; with centralized efforts benefitting from rapid isolation sided by diagnostic tests. Lessons learned from HIV highlights the importance of working with community-based organizations to engage most-at-risk populations. Since in COVID-19 is impossible to afford immense numbers of affected patients, using community intensive testing, and triage of those in need will be vital not to overwhelm medical care personnel and available scarce resources.

Dominican Republic's COVID-19 response is a hybrid of previous experiences in other latitudes, based on epidemiological characteristics of individuals, clinical progression of COVID®19, and quarantine intervention reinforced by the authority. Prevention against SARS-CoV-2 in the DR had involve massive disinfection campaigns, educational resources, community-engagement, case detection, and cluster isolation.

Now, when cases are declining in Europe, the next epicentre seems to be our continent, then, what is next for the Latin American region? The most crucial point is the identification of past successful outbreak control implementation actions and figures on how to adapt it to the COVID-19 needs. Since every Latin American countries relies on different funding mechanisms to fight it, and have different cultural behaviours, successful past experiences are quintessential. Countries must intensify their efforts in the detection of cases, isolation of those that can transmit it, and reduce the harm of severe illnesses and save lives.

Back to the DR, a more focused implementation of these premises are carried out, mostly based on RTPCR detection and focused among symptomatic patients, following the Chinese model of intensive case tracing 9 and limiting new transmissions with domiciliary or hospitalized isolation. Increasing testing using this molecular platform is costly, and will be limited by health insurance coverage, trained personnel, and government resources. During the third week of March, the government has announced a massive campaign of COVID-19 rapid testing with the aim to increases testing capacity, and focuses the RT-PCR to confirm cases. Therefore, the Dominican Republic still will need to reinfore population-based interventionsincluding aurantine and social distancing Onine social media campagns are uring people to stay at hocial in addion to are urging people to stay at home, in adition to a national nocturnal lockdown; people seem to understand the importance of social distancing. These measures are less costly and seem to facilitate the flattening of the incidence curve.

In conclusion, increasing testing will provide a detailed geographic distribution of positive cases, and keeping people infected in hospital-based isolation, 
following biological markers that facilitate early management of syndromic complications. This relies in the capacity of sufficient and robust health system to treat the sick and protect health workers, assisted by community navigators, providing continuous and accurate communication through media engagement, such as messaging via social media, WhatsApp, and other internetbased approaches could minimize people's risk behaviours, finally mitigating the impact of this disease.

Even though the need for testing is vital, this should never be done blindly but always with clinical consideration due to the likelihood of other circulating pathogens (e.g. Dengue, Malaria, respiratory viruses) or COVID-19 misinterpretation $[5,12]$. It is imperative to reinforce lockdowns based on well-defined rules and to explain the benefits of social distancing to very hard to reach communities. COVID-19 strategies shall be focused on community leader mobilization in high incidence spots and emerging hotspots, with clear political leadership by governmental authorities. In this, the political leadership with the guidance of experts will be trusted and civilians will assume the responsibility of staying home. Very soon we will see the impact of this virus in the continent, late adopters of international health regulations will face the worst scenarios, those with a more resilient programming are having better outcomes. As effective those interventions, as faster will be the economic recovery.

\section{Collaborators}

Authors' Contributions: RPR and LT conceived the work, analyzed the data, and wrote the manuscript. Both authors read and approved the final manuscript.

\section{REFERÊNCIAS}

$\begin{array}{lrrr}1 . \quad G l o b a l \quad H e a l t h & \text { Security Index } 2019 \\ \text { https://www.ghsindex.org/ } & \text { [accessed } & \text { 26.03.2020] }\end{array}$

2. Direccion General de Epidemiologia, Ministry of Health. COVID-19 Special Bulletins. https://www.msp. gob.do/web/?page_id=6682 [accessed 30.04.2020]

3. Peña F, Pimentel R, Khosla $S$, et al. Zika Virus Epidemic in Pregnant Women, Dominican Republic, 2016-2017. Emerg Infect Dis. 2019; 25(2):247-255. doi:10.3201/eid2502.181054.
4. Ribas Freitas AR, Alarcón-Elbal PM, PaulinoRamírez R, Donalisio MR, Excess mortality profile during the Asian genotype chikungunya epidemic in the Dominican Republic, 2014, Trans of The Roy Soc of Trop Med and Hyg. 2018;112(10):443449. https://doi.org/10.1093/trstmh/try072

5. Tapia L, Arredondo-Abreu C, Ruiz-Matuk CB, PaulinoRamirez, R. Is Climate the great driving forcé behind Dengue infections in Urban areas? A study in DengueEndemic Santo Domingo, Dominican Republic. Trans Roy Soc Trop Med Hyg. 2019;113(Suppl.1):S1-S98. https://doi.org/10.1093/trstmh/trz094

6. Barrington C, Acevedo R, Donastorg Y, Perez M, Kerrigan D.'HIV and work don't go together': Employment as a social determinant of HIV outcomes among men who have sex with men and transgender women in the Dominican Republic, Global Public Health. 2016;12(12):15061521. dOI: 10.1080/17441692.2016.1160141

7. International Committee on Taxonomy of Viruses. https://talk.ictvonline.org/. Accessed 30 March 2020.

8. Hou C, Chen J, Zhou Y, et al. The effectiveness of quarantine of Wuhan city against the Corona Virus Disease 2019 (COVIDQ19): a well囚mixed SEIR model analysis. J Med Virol. 2020;1- 8. https://doi.org/10.1002/jmv.25827

9. Li Q, Guan X, Wu P, Wang X, Zhou L, Tong $Y$, Ren R, Leung KS, Lau EH, Wong JY, Xing $X$. Early transmission dynamics in Wuhan, China, of novel coronavirusinfected pneumonia. New Eng J Med. 2020 Jan 29.

10. Pisano G, Sadun R, Zanini M. Lessons from Italy's response to Coronavirus. Harvard Business Review, March 27, 2020. [Accesed on April 30, 2020]. https://hbr. org/2020/03/lessons-from-italys-response-to-coronavirus

11. Altmann D, Douek DC, Boyton R. What policy makers need to know about COVID-19 protective immunity. The Lancet, April 27, 2020.

12. Yan G, Lee CK, Lam LTM, Yan B, Chua YX, Lim AYN. Covert COVID-19 and false-positive dengue serology in Singapore. The Lancet Infectious Diseases 2020;20. DOI:10.1016/s1473-3099(20)30128-6. 